\title{
SPECIALIZED AUTOMATED SYSTEM FOR CONTROL AND SUPPORT OF RAIL CARGO TRANSPORTATION
}

\author{
Andrii Fomenko ${ }^{1)}$, Volodymyr Vyshnia ${ }^{2)}$ \\ 1) Dnipropetrovsk State University of Internal Affairs, Gagarin Avenue, 26 Dnipro, Ukraine, mail@dduvs.in.ua \\ 2) Department of Economic and Information Security, Dnipropetrovsk State University of Internal Affairs, \\ Gagarin Avenue, 26 Dnipro, Ukraine, vishnyavova@ukr.net
}

Paper history:

Received 8 February 2019

Received in revised form 8 May 2019

Accepted 3 June 2019

Available online 30 June 2019

Keywords:

cargoes;

weigh checkpoint;

railway;

network;

threats;

information support;

automated information system.

\begin{abstract}
Today, Ukraine has faced the significant problem of railway cargo theft during transit and in the parking lots. Large losses of railways in this case require intensification of the fight against these crimes. The objective of the research is to find out the ways for preventing cargo encroachment by creating a network of weigh checkpoints (WCPs) on the railroad, which is intended for automatic control of the actual weight of goods in train carriages without moving them with further comparison of the accompanying data of cargo documents using electronic communication. In the event of a discrepancy between the indications of WCP device and the accompanying information on the loads, there is a fixed shortage of cargo in the carriage. The optimization of the general demand for WCP on the railways in practice allows law enforcement officers to use the research carried out as a means to effectively prevent crimes on the railroad.
\end{abstract}

Copyright (C Research Institute for Intelligent Computer Systems, 2019.

\section{INTRODUCTION}

\subsection{PROBLEM STATEMENT}

Being one of the most important branches of the economy, rail transport in Ukraine provides the proper functioning of industrial and agricultural production, uninterrupted and reliable delivery of goods. Today rail transport system in Ukraine ("Ukrzaliznytsia") accounts for more than two-thirds of the country's total cargo turnover.

Freight and passenger transportation in Ukraine is carried out by 6 railways subordinated to "Ukrzaliznytsia" - Donetsk, Lviv, Odesa, South, Southwest and Prydniprovska, which include functioning 1552 stations, 458 linear enterprises (locomotive and wagon depot, distance tracking, power supply, alarm and communication systems), and a sufficient fleet of wagons and locomotives. The traction rolling stock comprises 1848 electric locomotives and 2947 main and shunting diesel locomotives.

The railway transport is currently used by more than 12.5 thousand cargo owners. Railway stations serve 886 access roads to industrial enterprises, including 7 sea and river ports [1].

The nomenclature of goods transported in wagons by railway is diverse, but the main transported goods are iron ore and non-ferrous iron ore, metal (metal products and scrap), coal, building materials.

"Ukrzaliznytsia" also takes an active part in the international transit cargo transportation of the Moldavian, Byelorussian and other railways of the former Soviet Union, as well as Poland, Hungary, Slovakia and other countries of the near and far abroad [2-4].

All this is shown for pointing out the important place of "Ukrzaliznytsia" in the freight transport system, at the same time law enforcement agencies state that there is a serious problem of cargo theft during transit $[5,6]$.

In general, according to the report of the National Police Agency of Ukraine 28226 commercial acts have been drawn up regarding cargo thefts on the railway over the last years, but only 1532 criminal charges were laid by law enforcement agencies [7], 1244 of which were brought to the court. 
It should be mentioned that nowadays this problem is not only the problem of our country. The law enforcement agencies of neighboring countries, in particular Russia, Moldova, Poland, Germany, and the Netherlands face the similar challenge.

It should be noted that thefts of certain goods, in particular scrap metal and rolling stock take place not only in parking lots of freight trains, but also during their movement that sometimes leads to accidents, considerable material losses and deaths of people that requires investigating these crimes.

Thus, cargo theft on railways is one of the most dangerous and complex types of crimes, a characteristic of which is that the theft and the place where it has been committed as a rule do not coincide, being apart from each other at a considerable distance and even in the service sector of different police departments.

In order to identify the reasons for the lack of efficiency in the activities of the police departments in counteracting cargo thefts and formulating guidelines for improving the indicators of crime detection and prevention on railways, the survey among 116 police officers and 180 railway workers was conducted. $51.7 \%$ of the police officers involved in the survey consisted of investigators, and $48.3 \%$ were employees of the Departments (now sectors) of Combating Criminal Offences on Cargo (CCOC).

Among the contingent of police officers surveyed, $69.6 \%$ had higher education $(45.1 \%$ of them had legal education), $20.7 \%$ had secondary technical education. The corresponding figures among railway workers who took part in the survey were $48.9 \%$ and $27.8 \%$.

Poor standards of living of the population are considered by respondents as one of the reasons for committing mercenary crimes in freight transport $(18.2 \%)$, the possibility of direct penetration into wagons by means of a simple metalwork tool (23.1\%), poor cargo protection (15.7\%), large ordinary wagons at junction and other stations (40.3\%).

More than $68.2 \%$ of police officers consider the use of modern technical means of automatic control of cargo availability in wagons during their transportation to be an effective measure to combat the cargo theft on the railways.

Among the factors that mostly reduce the efficiency of crime detection and investigation in freight traffic, $61.7 \%$ of investigators identified the lack of operational information about the fact of cargo theft and the possibility of detecting crimes hot on the trail.

The respondents among the railway workers believe that the following measures could be the most effective in improving the activities of detection and investigation of abductions: escorting freight trains by police officers and paramilitary protection of the Armed Forces of Ukraine (81.1\%), the use of a network of weighing and weigh check points $(43.9 \%)$.

\subsection{ANALYSIS OF RECENT RESEARCH AND PUBLICATIONS}

Inadequate information security provided by the police regarding unreliable transportation and the need to strengthen the scientific, technical and informational support of the activity of the law enforcement bodies on railway is highlighted in the work. The low effectiveness of the use of existing card account records on the railways due to their local nature and the complexity of keeping cards on files and the need to extend the use of mathematical methods of data processing and the use of computer equipment is shown in the study.

A need for wider use of modern information analytical and retrieval systems for fighting against crime on the railways was highlighted in recent papers of Ukrainian scholars [14-19].

Active research on safety of cargo and freight trains is carried out in China [20]. Unfortunately, the majority of published results are aimed only at the development of logistic techniques and tools that ensure the reliability of information transfer regarding trains, and aimed at ensuring safe routes.

The extended world research is devoted to the fight against masked theft on the railroad, namely, fraud with the use of computer technology.

Early fraud detection committed with the use of computer technology is complicated because of the high latency level of this type of crime and wide opportunities for criminals to conceal the traces of the crime, namely:

- non-obviousness of crimes committed using electronic access means;

- the complexity of offender personality detection in the case of unauthorized access to the data bank of the PC or computer network;

- the availability of special technical knowledge in perpetrators;

- the possibility of committing a crime from an inaccessible place through telecommunication networks.

In addition, there are several ways to commit this type of crime, in particular:

1) interception of information containing passwords for access, direct connection to the network of computers and interception of electromagnetic pulses, the search for unsecured data in a computer, computer printouts;

2) computer information manipulation - the replacement of data, the destruction of the original 
information, the introduction of new teams in the program;

3) using "virus" programs for destruction of software protection, failures in the system, the destruction of the traces of the crime.

Thus, the results of the railway sector tasks for protection of cargoes and infrastructure against cyber attacks are presented in studies [21]. The fact is that today wired and wireless networks used on railways are usually heterogeneous, and they are not sufficiently protected and do not meet the requirements of cyber security in terms of stability, protection and detection of cargo attacks. In spite of the rapid development of telecommunication tools and devices, scientists have not taken into account aspects in this context.

A system of Indian Railways is one of the major railways in the world, covering more than 63,000 kilometers of daily traffic, with a load of 1.6 million tons of cargo. Under the information technologies Vision 2012 announced in the railways budget for 2008-09 and 2009-10, the Ministry of Railways has considered the possibilities of switching to advanced technology to improve efficiency and reduce the cost of transportation [22].

Improvizing systems have been created recently for Indian railways, which can be used not only to account gateway issues, but also for control over cargo traffic [23].

Today, the railway industry is in a position where it can take advantage of the opportunities created by the IoT (Internet of Things) and supporting communication technologies within the paradigm of Internet trains. In the work [24], the evolution of GSM-R communication technologies was considered; basic requirements and recommendations of the industry development were shown. The benefits of the latest generation of broadband communications systems (such as LTE, 5G, IEEE 802.11ad) and the appearance of a wireless sensor in the network for railways show positive effects and achievements in the development of automated networks.

The closest to the solution of the automation of the cargo custody control process is the introduction of the centralized information system of the AIRS "Cargo-TM" in Russia, which is intended for centralized collection, storage, systematization and data collection (from card files) of the theft of goods and baggage facts, under which criminal proceedings were initiated [25].

At the same time, the given AIRS does not eliminate the reasons that complicate the timely detection and investigation of cargo hijackings, more specifically, the system does not have the information of the operative notification of the police units about the fact of the abduction and objective data on the place and time of the commission of the crime.

If all the above to be summed, the main reason for the lack of effectiveness of the fight against theft of goods on railways is the lack of theft evidence in a particular section of the railway and the time of its accomplishment, operational control over the goods transported on the way from the supplier to the recipient.

Therefore, the purpose of this article is to outline the results of the development of a specialized automated electronic network for the operational control of the safety of goods while transporting by railway.

The effectiveness of the results is expected due to the creation of modern systems of weight control at certain railway stations, which are connected to each other and to the computer centers of the railway lines.

\section{PROPOSED APPROACH}

\subsection{THE IDEA OF AN APPROACH WITH INFORMATIVE ASPECTS}

The ways of solving the problem of the fight against the abduction of cargoes on the railways, formulated by the authors, are seen in the development of a specialized system of technical control and accompaniment of transported cargoes. Within the framework of the concept presented above, it is proposed to equip weigh checkpoints (WCP) at nodes, junctions and large railway stations, which would carry out the weighing of wagons with highly liquid cargo, in motion, without unbundling cars. To fulfill the functions entrusted by law enforcement bodies to the WCP, they must be merged into a single electronic control network for freight transportation on the railways.

Within this network, in the direction of the traction with the cargo, from one WCP to the other, the information of the actual sheet on the train should be transmitted, such as the serial number of the wagon with the load in the train, the weight of the wagon and the load, the shipment and destination station.

In the case of a discrepancy between the indication of the control equipment at the WCP and the accompanying information on the load, the lack of cargo in the car would be fixed and the relevant information forwarded to the police and railway departments. That is, we have an example of a quick response to the fact of committing a crime, which would allow them to "reveal" and investigate more effectively "fresh" tracks, to make the right managerial and organizational decisions [26].

With regard to information outlined above, specialists of Dnipropetrovsk State University of 
Internal Affairs, at the request of the Ministry of Education and Science and the Ministry of Internal Affairs of Ukraine, developed and proposed the introduction of a specialized automated system for monitoring and escorting freight transportation on the railways. The latter one (Fig. 1) includes a number of WCPs located at the junction and node stations of the rail (WCPi), and a network of communication between them and the information and computing centers of the railways (ICSi).

The proposed idea is protected by the Patent of Ukraine № 8927 “A method of monitoring the safety of cargo transportation by rail" [27] and implemented as a network in Fig. 1.

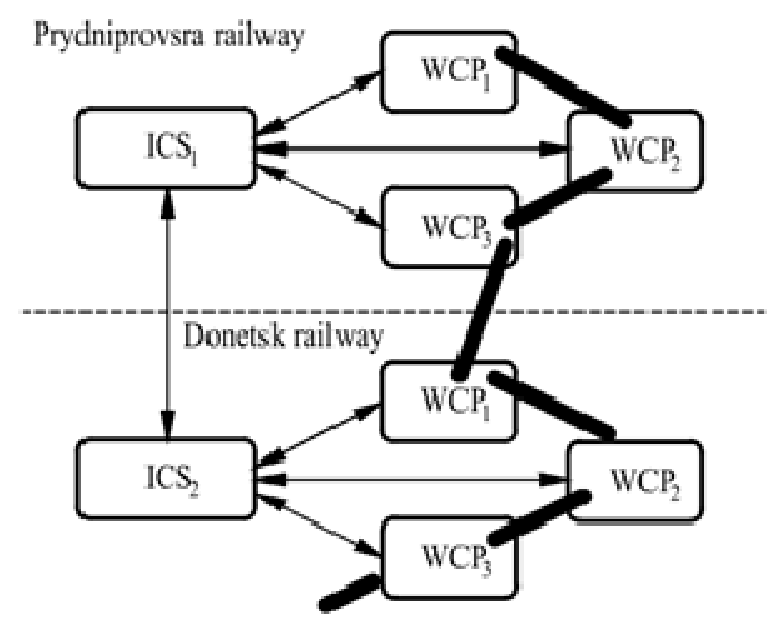

Figure 1 - General scheme of the specialized automated control and escort system of cargo transportation on the railway; where black lines railroad tracks.

The WCP (Fig. 2) carries out the weighing of the wagons with the load of the train and compares the measured values with the data of the actual information about the cargo received on the network connection from the previous WCP or train formation station. The results of weighing the cargo on the WCP are sent to the next weight control point in the direction of the train for further control of the safety of the goods being transported.

The study, conducted by the authors, made it possible to formulate the requirements for logistics of the WCP and the metrological parameters of the measuring devices, to offer the introduction of specific technical means of cargo control, accompanying and accumulative documentation, and necessary forms of control documents (Fig. 3).

At the same time, while creating a network of WCP a question about information support of the proposed technical solution was raised.

In the first place, this concerns the choice of subordination of the electronic communications network, that is, the railway or the police. The advantage of the railway communication network is that it already exists, there is some experience in the transfer of data to the actual sheet, and the network is close to the computer centers of the railways. The disadvantages include relatively simplified access to this information for those who may be interested in seizing the information of the WCP, as well as the ability to block, change or spoil it.

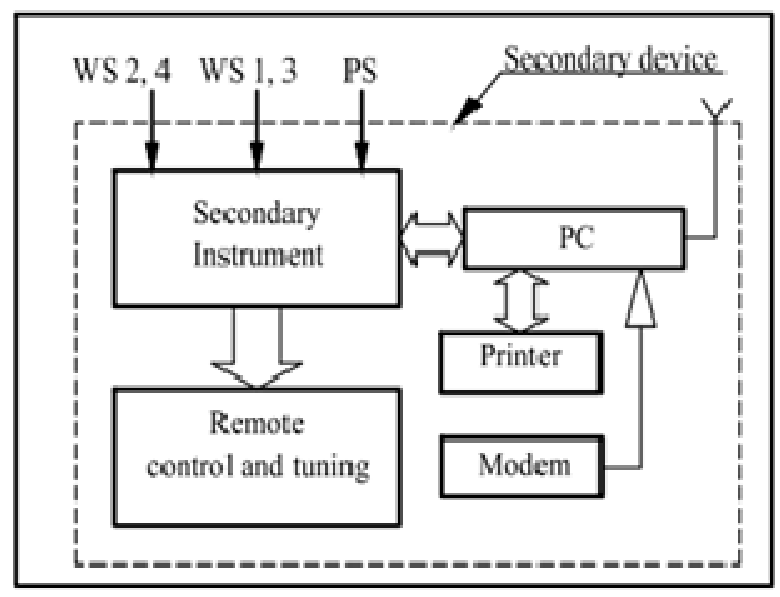

Figure 2 - Structure of the electronic weighing system for cargo control on the railway: WS - weight sensors, PS - position sensors

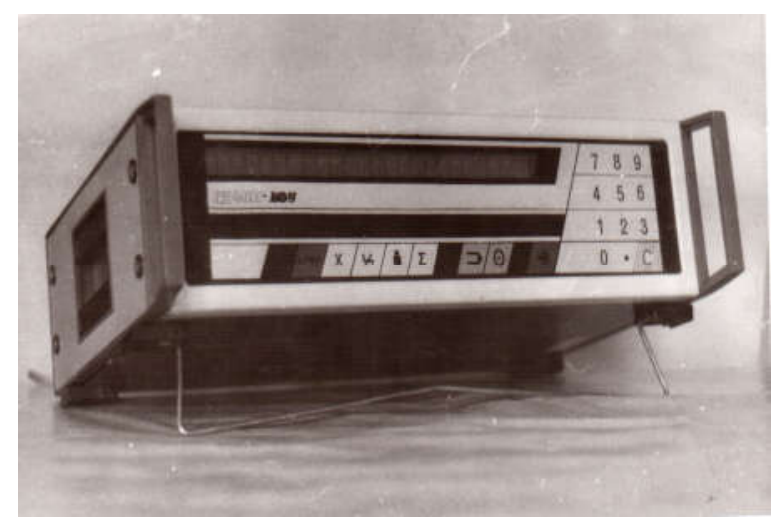

Figure 3 - Secondary device of WCP

The creation of a corporate electronic network of police between the WCP would require serious investment and the need to create a cargo database on the railways. At the same time, the presence of a separate police network would enable the transfer, along with general information about the cargo, of the information that must be under secrecy: data on similar crimes (by type of cargo) in recent times, information on criminal groups operating in this area of the road, etc.

Thus, the conceptual decision of the network's jurisdiction requires a detailed examination of many factors that affect the technical, financial and departmental features. 
The use of the proposed WCP on the railways would also allow localize the areas of the railroad (between the two WCPs), where theft had been committed, and the schedule of train movement to set the time of passing each conditional point in this area, which would greatly facilitate the investigation of the crime.

For the system of functions assigned to it by the police, the secondary equipment of WCP (Fig. 2) should include: a specialized software and debugging device for measuring and processing the signal of load sensors and the allocation of the mass of the transported cargo; device for identifying the axes of the car and cutting off the locomotive (locomotives); a computer for storing and processing information about cargoes and trains, maintaining the history of the process, forming a message when detecting the inconsistency of the mass of the load in the carriage (the presence of theft); printer for recording protocols and forms on a paper carrier; a modem for messaging with senders and recipients of cargoes, other weighing points on the way of trains passing; autonomous voltage source.

Within the framework of the outlined above, we propose information support of the electronic network, aimed at the control and freight transport escorting on the railways in order to prevent and investigate cargo thefts, as a complete structure of the infographic computer environment and the use of cloud computing AIS "Orion-Luggage” (Fig. 4).

The "Cargo" subsystem would allow to receive and process information through the communication channels about the expected arrival at the freight station of the freight traffic police unit of certain loads, wagon guards and conductors, the data of the actual information sheet on the train and the places of crossing the routes by other freight trains.

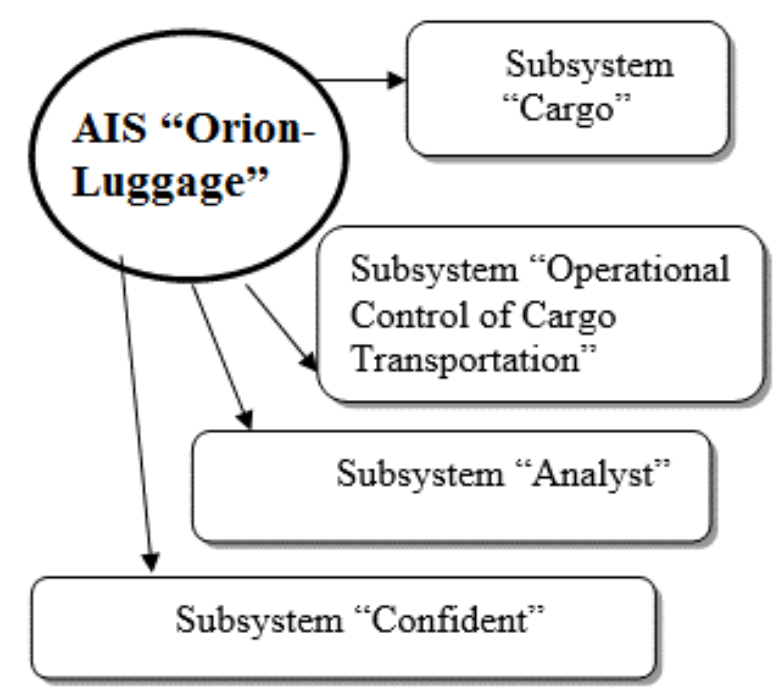

Figure 4 - General structure of AIS “Orion-Luggage”
The subsystem "Operational control of cargo transportation" on WCP carries out control over the availability of cargo and the compliance of its data with accompanying documents and issues the necessary electronic and paper forms on the state of the safety of freight.

The evaluation of the obtained summary (subsystem "Analyst") mainly includes the analysis of some information in terms of its objectivity and usefulness for this investigation. The analysis of information is mainly prepared by the staffs that collect it and have all the data on both the information to be evaluated and its source. At the same time, in our opinion, it is expedient while evaluating information provide data on the reliability of the source, as well as the degree of its value.

An important part of the analysis is the systematization of information, that is, available information or input data is collected in a certain logical sequence, which allows to understand the essence of criminal activity.

Information for analysis could come from a multitude of different sources of varying degrees of reliability, while it does not come in chronological order and more often relates to a number of episodes concerning persons suspected of committing cargo thefts. Therefore, all data must be systematized in such a way that the most important interconnections can be identified.

In our opinion one of the directions of improving the use of AIS "Orion-B" is the development and introduction of a subsystem "Confident" with a task related to those who provide confidential support to the operational police units.

\subsection{OPTIMIZATION OF WCP PLACEMENT}

For the effective use of WCP, it is necessary to take a number of organizational measures that would determine the appropriate locations of the WCP on the railways (at junction, node and other stations, access roads to the valuable goods suppliers) and types of routes which are subject to control.

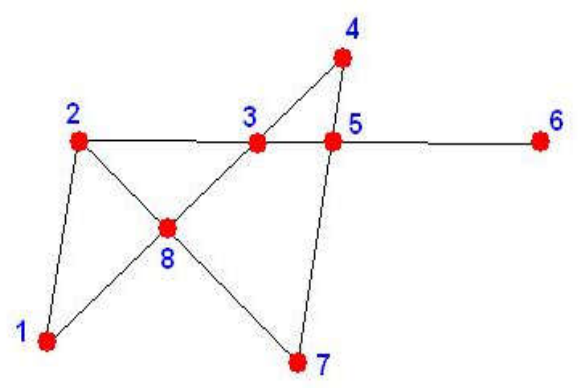

Figure 5 - Associated unoriented graph 
It is interesting to use the graphs theory to solve the problem of the number of WCP locations which would completely block all the ways of goods transportation by railway with a minimum equipment costs and maintenance of the WCP. That is, it is needed to solve a generalized problem. For this purpose, we developed a mathematical model of one of the railways [28].

The railway system of the region is modeled as a linked non-oriented graph (Fig. 5). The non-oriented graph $\mathrm{G}(\mathrm{S}, \mathrm{P})$ consists of a finite set of vertices - S and sets of pairs of elements from $\mathrm{S}$ vertices $P \supseteq S \times S$ - ribs that tie the vertices. The vertices are the railway stations, and the ribs are railway tracks that connect them.

The process of problem solving can be divided into several stages.

As it was mentioned above, the graph $\mathrm{G}(\mathrm{S}, \mathrm{P})$ would be bound in our case, since, according to the problem statement, there is a path for any two vertices to connect them.

The optimization conditions are determined by $\mathrm{k}_{\mathrm{opt}}$ criterion optimization, which is set by the user. On the basis of problem statement (connectivity G $(\mathrm{S}, \mathrm{P})$ ) the $\mathrm{k}_{\mathrm{opt}}$ condition must be fulfilled for the criterion where $\mathrm{k}_{\mathrm{opt}}$ is the number of other vertices connected to this vertex.

The algorithm for solving the optimization problem includes the following. The OPUZ software product was created by means of Visual FoxPro 6 (VFP6) to optimize the location of WCP, which consists of the following parts.

1. Entering information on graph $G(S, P)$ vertices. The class of objects, that is st_dot points, was created. These points can be implemented on the container object during program execution. Then, the map of selected region railways is applied on the information input form and, finally, the st_dot points, which are graph $\mathrm{G}(\mathrm{S}, \mathrm{P})$ vertices, are entered (Fig. 6). In the process of this algorithm implementation we had to solve a non-trivial task of creating a unique name, a dynamically introduced object with uncertain initial data, which was caused by the need for further work with this object in the program execution mode, and filling the database about the vertices of the graph $\mathrm{G}(\mathrm{S}, \mathrm{P})$ - a table st_coord.

2. The graph of railway tracks implementation. Just as in the case of entering information about the vertices of the graph, a class of dot line points objects was created and an algorithm for drawing continuous lines (the P ribs of graph $\mathrm{G}(\mathrm{S}, \mathrm{P})$ ) was implemented between the connected stations by using these points. Directly on the map there were objects constructed in the class st_dot, the rib of the graph was carried out and the result was entered in the table st_conct, which stores information about the links between the stations - the vertices of the graph (Fig. 7).

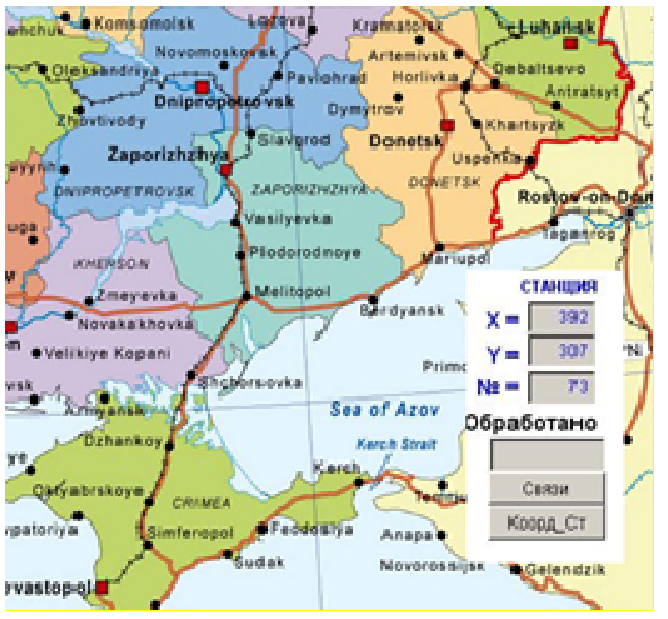

Figure 6 - The vertices of the graph $G(S, P)$

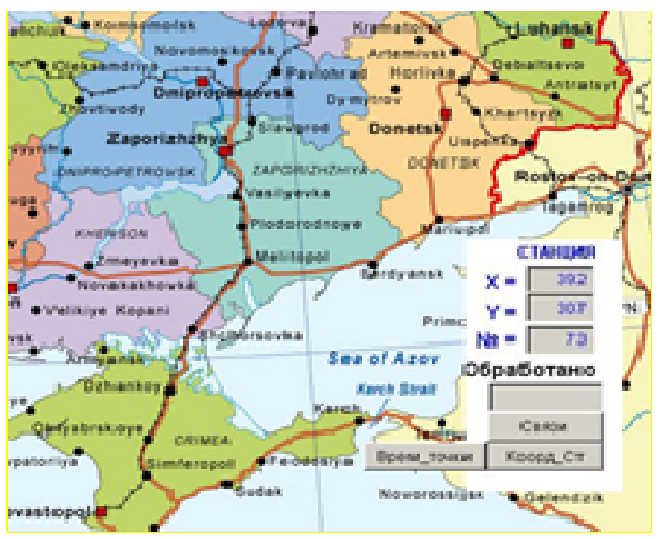

Figure 7 - The edges of the graph $G(S, P)$.

3. The matrix of bonds construction. The matrix of the connections A_connect $(i, j)$, where $i$ and $j$ are the corresponding vertices of the graph, is a twodimensional array. The matrix elements can take two values:

$A_{-}$connect $(i, j)=\left\{\begin{array}{l}\frac{0-\text { no connection }}{1-\text { there is a connection }} \\ \text {. }\end{array}\right.$

Data on connections between stations (for example, A-B) were entered into the contact table st_conct by the operator from the map without sequence observance, which reflects all the station communications input. That is why, this data was also supplemented by the connections of type (B-A) to create a complete connection table st_conct_f in the future.

4. Solution of the optimization problem. Taking into account the number of links for each of the vertices of the graph (cnct_opt table) and the chosen optimization criterion (kopt $\geq 2$ is taken by default), an optimal number (17) of the WCP and the location 
of the railway stations that could be recommended for the placement of weighing points were determined.

We shall consider the structure of optimal route search algorithm on the map ("Vector search in depth").

There is a quite large number of algorithms for finding an optimal path on the graphs and for a wide range of tasks:

1) The Dykextree algorithm is used for tasks with a small number of vertices of a graph. Based on a simple overlay of vertices with minimization of the total distance (the sum of the weight of the ribs from the initial vertex to the finite one) [29].

2) Search in depth refers to well-known search methods the essence of which is the following: if we know where the target vertex is, we will take all of them in turn until we encounter it. However, there is a certain choice. While searching in depth, the first neighbor of the current vertex on the list is analyzed, then, its second neighbor is analyzed, etc. If some vertex has no neighbors, then the second neighbor of the vertex considered is analyzed. Thus, the search procedure immediately reaches the vertices, far from the starting point, and only when it reaches the vertex that has no neighbors, returns back [30].

3) Search in width also refers to informed search methods. While searching for width, all neighbors of the current vertice are analyzed at first. Then, neighbors of neighbors, neighbors of neighbors of neighbors, etc. until the procedure considers all the vertices that are at graph edges distance from the start transition to distant vertices [31].

It should be noted that all these algorithms operate with square matrices of dimension $\mathrm{n} \times \mathrm{n}$, where $\mathrm{n}$ is the number of ribs. Consequently, with an increase in the dimension of the graph, the volume of computations increases sharply in proportion to $\mathrm{n}^{2}$. The situation can be improved by the introduction of so-called "heuristic functions", but these methods remain ineffective.

In solving this problem, we encountered the difficulties described above, which led to the need to search for a new algorithm, which we called "Vector search in depth". There is a certain similarity to the algorithmic operation "Search in depth" in work [29]; the difference lies in the fact that this algorithm implements it "consciously".

While implementing "Vector search in depth" algorithm the authors abandoned the matrix approach to representing the links (ribs) between the vertices of the graph and implemented it by using the connectivity table which greatly reduced the amount of computation. For example, Pridneprovskaya railway was modeled in the first approximation with a graph of 40 vertices and 60 ribs, that is, the dimension of the matrix of connectivity is $60 \times 60$ and it contains 3600 elements, and the connection table contains only 120 elements.

The basic idea of the method lies in the maximum orientation of the vector connecting the current vertex of the graph to the finishing point. That is, at each step of the calculation algorithm, the vectors that connect this vertex to the neighbors are determined and the neighbor for which the angle between the corresponding vector and the vector directed to the finishing station is minimal has been chosen. In other words, the self-tuning of the direction to the finishing point takes place at each step of the computational algorithm. As in the case of other algorithms, the problem of eliminating dead ends (points that have only one neighbor) is also significant. This problem was eliminated by the introduction of the module, which takes a "look" one step ahead, and determination of the degree of each vertex associated with this (the number of vertices associated with it).

It should be highlighted that the authors do not claim to use this algorithm to solve any task of finding the minimum path. However, with regard to finding the best route on the map, it showed very good results, especially the use of the unit for assessing the degree of new vertices.

The following studies have been conducted and presented in this section:

1. A mathematical model of Pridneprovsky railway in the form of a non-oriented graph has been constructed.

2. The algorithm for solving the problem of finding the optimal route from one station to another has been developed and implemented, which allows to identify the stations of maximum load, on which heavy control points of the network of electronic goods support should be placed.

In order to reduce the total number of WCPs it is expedient to introduce some restrictions in the future, in particular to prohibit the transportation of highly liquid cargo on the separate railway sections, but not on the main ones (that is, it will not be possible to direct loads around the large stations and stations equipped with points of commercial inspection). It will also affect the total number of WCPs and their locations.

\section{CONCLUSIONS}

The railway transport in Ukraine is an economic sector that determines the state and stability of regional development, provides domestic and external transport and economic relations.

The results of the research presented in the article lie in the fact that the authors have formulated for the first time the principles of the structure of specialized automated control system and cargo 
transportation escorting on the railway. The technical and program solutions proposed make it possible for police to fight against cargo theft effectively due to clearer determination of crime scene location.

The article focuses on general theoretical and methodological basics of using methods and means of optimization (based on the theory of graphs) of WCP electronic network of cargo forwarding.

The implementation of the automated system of WCP on the railways allows us to discover the fact of cargo theft on WCP, through which the train follows, quickly and efficiently. That is, the information of the WCP will be the main type of messages about cargo theft.

Optimizing the location of WCPs at railway stations will make it possible to reduce costs of system development and use the amount of WCPs that is sufficient to cover all the routes of highly liquid cargo transportation.

It is important for practical functioning of the system to assess the level of information security in the system, vulnerability of individual elements and the network in general in the future.

\section{REFERENCES}

[1] Handbook of the Cargo Owner. Dnipropetrovs'k: Publishing House of the Pridniprovs'ka Railway, 2002, 268 p. (in Ukrainian).

[2] Listed on half-way, and with the laying of contracts on the organizer of international transport, Kiev: "Ukrzaliznytsia", 2018. www.uz.gov.ua/cargo_transportation/general_i nformation/per_per/.

[3] E.A. Abdelhafiez, M.R. Salama, M.A. Shalaby, "Minimizing passenger travel time in URT system adopting skip-stop strategy," Journal of Rail Transport Planning \& Management, vol. 7, issue 4, pp. 277-290, December 2017.

[4] T. Liden, T. Kalinowski, H. Waterer, "Resource considerations for integrated planning of railway traffic and maintenance windows," Journal of Rail Transport Planning \& Management, vol. 8, issue 1, pp. 1-15, June 2018.

[5] Results of work of the bodies and units of the Ministry of Internal Affairs of Ukraine for the control of theft of goods and disassembly of rolling stock at the Pridniprovs'ka railway, Dnipro: BWRW of the Ministry of Internal Affairs of Ukraine, 2016. (in Ukrainian).

[6] L. Kroon, G. Maroti, L. Nielsen, "Rescheduling of railway rolling stock with dynamic passenger flows," Transportation Science, vol. 49, issue 2, pp. 165-184, 2014.

[7] P. Arnold, D. Peeters, I. Thomas, "Modelling a rail/road intermodal transportation system," Transportation Research Part E: Logistics and Transportation Review, vol. 40, pp. 255-270, 2004

[8] Y.M. Bontekoning, C. Macharis, J.J. Trip, "Is a new applied transportation research field emerging? - A review of intermodal rail-truck freight transport literature," Transportation Research Part A: Policy and Practice, vol. 38, pp. 1-34, 2004.

[9] Securing Control and Communications Systems in Rail Transit Environments. Part II: Defining a Security Zone Architecture for Rail Transit and Protecting Critical Zones. APTA Standards Development Program. Recommended Practice. American Public Transportation Association. APTA-SS-CCS-RP-002-13. Published June 28, 2013.

[10] J.A. Zapata Cortes, M.D. Arango Serna, R.A. Gomez, "Information systems applied to transport improvement," Dyna, vol. 80, no. 180, pp. 77-86, August, 2013

[11] J. Kuhr, N. Ruiz Juri, C. Bhat, J. Archer, J. Duthie, E. Varela, M. Zalawadia, T. Bamonte, A. Mirzaei, H. Zheng, Travel Modeling in an Era of Connected and Automated Transportation Systems: An Investigation in the Dallas-Fort Worth Area, The University of Texas at Austin, Report No. D-STOP/2017/122, February 2017.

[12] A. Rosová, M. Balog, Ž. Šimeková, "The use of the RFID in rail freight transport in the world as one of the new technologies of identification and communication," Acta Montanistica Slovaca, vol. 18, issue 1, pp. 26-32, 2013.

[13] A. Beck, H. Bente, M. Schilling, "Railway efficiency - an overview and a look at opportunities for improvement," International Transport Forum, Discussion Paper No. 201312. [Online]. Available: https://www.itfoecd.org/sites/default/files/docs/dp201312.pdf

[14] Z.M. Lomako, P.Yu. Timoshenko, Application of Technical Instrumentality in the Activity of Operational Officers of Internal Affairs for the Prevention and Documentation of Offenses, Kiev, Ukrainian Academy of Internal Affairs, 2004, 36 p. (in Ukrainian).

[15] D. Lomotko, J. Zapara, V. Lyuti, "Modern approaches to the preservation of cargo during transportation by rail," Scientific Journal 
"ScienceRise", no. 5/2(4), pp. 15-19, 2014. (in Ukrainian).

[16] I.V. Krasnoselsky, "Theft of cargo by rail transport workers by falsifying and compiling fictitious commercial acts and ways of exposing them," Proceedings of the International Conference on Organizational and Legal Bases of Struggle Against Infringements on Transport, Odessa, November 29, 2013, pp. 142-143. (in Russian)

[17] B.U. Kutsenko, O.L. Christov, "Methods of theft of cargo in the railway transport," Proceedings of the Conference "Use of Special Knowledge in Pre-trial Investigation", Dnipro, May 13, 2016, pp. 123-125. (in Ukrainian)

[18] E.V. Krinichna, "Features of the review of the scene of events on the facts of cargo theft on the railroad," Forensic Bulletin, no. 1, pp. 117-120, 2013. (in Ukrainian)

[19] I.V. Berezovenko, Ye.V. Polyakov, "Some aspects of internal and external interaction of transport militia units in the fight against theft of cargo in rail transport," Southern Ukrainian Law Magazine, no. 4, pp. 150-153, 2014. (in Ukrainian)

[20] J.H. Liu, "Comprehensive evaluation method of railway safety risk based on FTA-AHP," China Railway Science, vol. 38, no. 5, pp. 138-144, 2017.

[21] Cybersecurity for Rail: Not a Single-Shot Approach: Applying the NIST approach to rail transportation, Thales Ground Transportation, White Paper, 2016.

[22] S. Anila, B. Saranya, G. Kiruthikamani, P. Devi, "Intelligent system for automatic railway gate control and obstacle detection, International Journal of Scientific Research \& Growth, vol. 4, issue 8, pp. 24-30, 2017.

[23] H. Dong, B. Ning, B. Cai, Z. Hou, "Automatic train management system development and simulation for high-speed railways," IEEE Circuits and Systems Magazine, vol. 10, issue 2, pp. 6-18, June 2010.

[24] J. Rodriguez-Pinheiro, P. Fraga-Lamas, H.A. García-Naya, L. Castedo, "Analysis of the long-term evolution of railway communications security," Proceedings of IEEE Congreso de Ingeniería en Electro-Electrónica, Comunicaciones y Computación (ARANDUCON'2012), Asuncion, Paraguay, November 28-30'2012, pp. 1-9.

[25] Forensic Methodology for Investigating Certain Types of Crimes, Edited by A.P Rezvan,
Moscow: IMC GUK of the Ministry of Internal Affairs of Russia, 2002. (in Russian)

[26] V.B. Vishnya, "Specialize in the development of the cradle of wardens in the hall of transport," Scientific Herald of Dnipropetrovsk State University of Internal Information: Collection of Sciences works, no. 2, pp. 315322, 2015. (in Ukrainian)

[27] O.V. Vishnya, "The way of the control of the burial-ground vantage-carrying on the hall," Declaration Patent, no. 8927, Ukraine, IPC 7 B61L13/00 / no. 200503376; Declared on April 11, 2005, Published 15.08.2005, Bulletin no. 8 . (in Ukrainian).

[28] V.B. Vishnya, "Methodology of constructing a model for optimization of placement of weight control points for controlling the theft of goods on railroads," Scientific Bulletin of the Dnipropetrovsk State University of Internal Affairs, no. 3, pp. 179-183, 2016. (in Ukrainian)

[29] E. W. Dijkstra, "A note on two problems in connexion with graphs," Numerische Mathematik, vol. 1, issue 1, pp. 269-271, Dec. 1959.

[30] S. Edelkamp, S. Schrödl, Heuristic Search: Theory and Applications, Morgan Kaufmann Publishers, 2012, 712 p.

[31] T.H. Cormen, C.I. Leiserson, R.L. Rivest, C. Stein, Algorithms: Construction and Analysis: Introduction to Algorithms, 2nd ed., Moscow: "Williams", 2006, 1296 p. (in Russian).

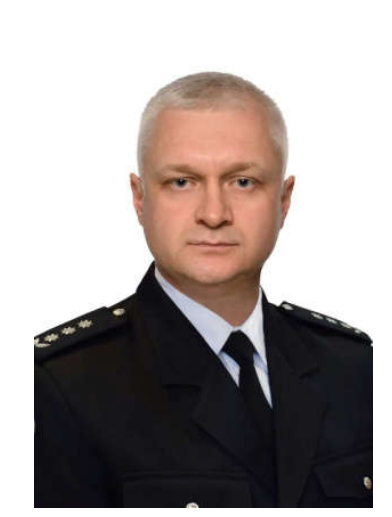

Fomenko Andrii was born in 1972. He graduated from Luhansk Academy of Internal Affairs (19901994). He had been working in Dnipropetrovsk State University of Internal Affairs since 2015 as the Vice-Rector, and since 2017 he has been holding the position of the Rector of the University.

$\mathrm{He}$ is actively involved in scientific activity, which results are implemented in the educational process of the university. He is the author of over 60 scientific works, including authored and co-authored textbooks, scientific and practical manuals, as well as professional papers published abroad in scientific indexed journals such as SCOPUS and Web of Science.

$\mathrm{He}$ is one of the inventors of the utility model, the implementation of this model has allowed to ensure the effective management of patrols in the 
practical activities of the National Police. He is the head of editorial boards of the legal professional journal "Law Herald of Prydniprovsk" and the "Scienticic Herald of Dnipropetrovsk State University of Internal Affairs, which is included in the international indexing database of Index Copernicus.

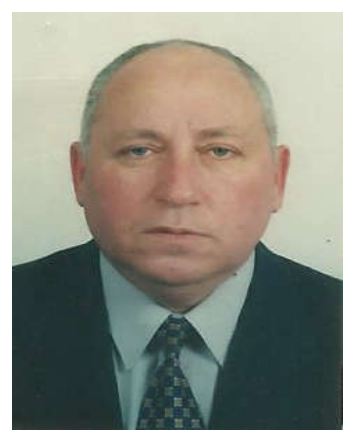

Volodymyr Vyshnia was born in 1947. In 1966 he graduated from college, and in 1972 he graduated from the university with a degree in "Automation and telecontrol". Since 2000 and till now he has been working as a professor of Economic and Information Security Department at

Dnipropetrovsk State University of Internal Affairs. Doctor of Technical Sciences in "Automation of Technological Processes" since 1998, professor 2002. The author of 184 scientific articles and reports, 25 patents of Ukraine, 32 textbooks.
He is a member of the three editorial boards of professional periodical publications in legal sciences, in particular, "Scientific Herald of Dnipropetrovsk State University of Internal Affairs", "Law Herald of Prydniprovsk" (founder: Dnipropetrovsk State University of Internal Affairs), "Current Problems of Ukrainian Law" (founder: Dnipropetrovsk National University named after Oles Honchar).

The member of specialized scientific councils of SCR 08.727.01. and D 08.727.02.

The main scientific activities are within the improvement of the automation means to fight cargo theft, improvement of the activities of the National Police in the fight against cargo theft in transport and protection of electric networks from unauthorized access, cable and air networks theft.

$\mathrm{He}$ obtained presidential scholarship for achievements and contributions to education and science (Decree of the President of Ukraine No. 43/2018). He holds a diploma of the honorary professor of Dnipropetrovsk State University of Internal Affairs, The Honorary Diploma of the Verkhovna Rada of Ukraine (dated March 19, 2018). 